\title{
On the Validity of Systemic Functinal Approaches as a Tool for Selecting Materials in CLIL Contexts. A Case Study
}

Laura Filardo llamas and Elena GonzÁlez-CAscos Jiménez University of Valladolid

LAURA RiESCO CANDUELA

CEIP. Miguel Hernández, Valladolid

Received: 4 November 2010 / Accepted: 5 December 2010

ISSN: 1697-7467

\begin{abstract}
The aim of this paper is to propose the validity of functional approaches within discourse analysis as a tool for selecting classroom material. By taking into account the linguistic realization of the three main contextual variables, namely field, tenor, and mode, and their impact on the function of language within each particular context of communication, we believe that the task of selecting and devising materials for CLIL setting shall be eased. This hypothesis becomes the point of departure for this article, where we present an analysis of six texts used for teaching Science using L2 English as the means of instruction. Conclusions are obtained about the importance of considering that any type of language used in a text has a function which depends on the context where it is used, an aspect which is frequently forgotten in L2 classrooms.
\end{abstract}

Keywords: Discourse analysis, Systemic Functional Grammar, Primary school, CLIL

Sobre la validez de los enfoques sistémicos funcionales como herramienta para la selección de materiales en contextos de AICLE. Estudio de un caso.

RESUMEN: En este artículo se pretende probar la utilidad que tienen los acercamientos funcionales al análisis del discurso para seleccionar material de aula. Al tener en cuenta la realización lingüística de las tres variables contextuales, el campo, el tenor, y el modo, y el impacto que éstas tienen en la función que tiene el lenguaje en determinados contextos de comunicación, se facilita la selección y creación de materiales para la docencia en un entorno CLIL. Esta es la hipótesis que se pretende comprobar en este artículo. Para ello se presenta el análisis de seis textos que se utilizan para enseñar conocimiento del medio en inglés como L2. A partir de ello, se extraen conclusiones sobre la importancia de la función que tiene el tipo de lenguaje que se utilice en cada texto, y cómo este varía en función del contexto en el que se utilice, un aspecto que con frecuencia se olvida en las clases de inglés como lengua extranjera.

Palabras clave: Análisis del discurso, Gramática sistémico-funcional, educación primaria, CLIL 


\section{INTRODUCTION}

The objective of this article is evaluating the validity of systemic functional grammar (Halliday, 2004) as a tool for choosing classroom materials. We depart from the hypothesis that teachers are not always aware of why they choose one material or another, or why one type of text suits the needs of some students and not others. Teachers in the Spanish education system frequently rely on textbooks and they rarely question the type of texts that are chosen and used in their English classes. A thorough thought about the process of selection materials resulted in some questions: Are native texts more suitable for teaching English through other subjects? Are the texts we use suitable for Content and Language Integrated Learning (CLIL) contexts? Is there any difference between texts produced in Spain - and spread through textbooks - and text used in a native Englishspeaking contexts?

In this paper, we will try to address some of these questions, particularly by relying on the postulates of Discourse Analysis (Brown \& Yule, 1983), the importance that is attached to context within this approach, and functional understandings of language (Halliday, 2004). Thus, we will try to make teachers aware of the importance of analyzing the characteristics of both oral and written texts. As an example, in this article we have performed the analysis of different texts used to teach Science to primary-school children in different contexts. Context becomes an important concept in this research, and the role that language has in different situations - and therefore its different functions - has to be emphasized. It is frequent to find a focus on language as the substance of what is being learnt in EFL, but we cannot forget that language in CLIL contexts is not only one of the learnt elements, but also the medium of learning (Halliday, 1999). Consequently, a discursive analysis of different texts can help teachers in selecting materials not only because they are written in English and they transmit the required contents, but also because the English employed in them corresponds to the one that is expected in order to fulfil its communicative function in a particular classroom context. Thus, contextual features as understood by Halliday (2004) will become the point of departure.

\section{Methodology}

The analysis that is carried out for this research is aimed at comparing different texts dealing with a similar content in terms of their contextual parameters. The importance of context in this research stems from a discursive understanding of language (McCarthy \& Carter, 1994) in L2 acquisition. Although current language teaching is based on a communicative approach, the influence of descriptive analysis of the discursive properties of language has been felt in language classes. Following the importance of describing language, it is common to find textbooks which focus on "single sentences or minimal units of language and on practising forms of language within such framework» (McCarthy \& Carter, 1994: xi).

As it has been mentioned before, in this article we argue that text analysis can become a useful tool for the teacher to select the classroom material. Language and discourse are not small and connected chunks of language, but the way in which they are connected is determined by the function they have in context. Aspects such as time, 
place, discourse participants, or topic determine linguistic choices, and therefore should be considered in the language classroom. We propose that materials should be chosen by relying on contextual parameters and their connection to the function of language, rather than on their appearance on a textbook. This can help both teachers and students focus on the acquisition of the appropriate language form used for communicating a particular meaning. This belief is thoroughly is connected to McCarthy \& Carter's (1994: xii) claim that «the better a text analyst the teacher can be, the better equipped [...] his or her students are likely to be in using the language appropriately».

Given the importance that is placed on context in this paper, the analysis will be based on uncovering the contextual features of a text by relying on its discursive properties. This can give the teacher knowledge about the topic and social activity, the participants and the type of relationship they have, and the time and place when communication takes place. In order to analyse this, we have focused on the connection existing between the contextual variables that define the situation and communicative functions (Halliday, 2004; Coffin et al., 2009: 213). As explained by Coffin et al. (2009: 213-228), there are three contextual variables which determine the way in which we use language - and in which we expect it to be used - namely «field» - the topic and social activity which is taking place -, «tenor»-the participants and their social roles -, and «mode - the way in which language is used. The combination of the defining features of these contextual variables result in a given «register», which is the outcome of the amalgamation of the three metafunctions of communication: ideational, because we always represent the world, interpersonal, as communication is always used to interact with other people, and textual, as language has to be used in a coherent and cohesive way. Even if we have no previous knowledge about the context where a given text is used, the analysis of certain linguistic categories can help us uncover that register. Thus, an analysis of different texts can result in a comparison of different registers, and subsequently in conclusions about the use of particular language forms for particular purposes. The ideas which underlie the proposal in this article can be seen in figure 1 .

$\begin{array}{lllll}\begin{array}{l}\text { Contextual } \\ \text { variable } \\ \text { Field }\end{array} & \Leftrightarrow & \text { Metafunction } & & \begin{array}{l}\text { Language (examples) } \\ \text { Ideational meaning }\end{array} \\ \text { Tenor } & \Leftrightarrow & \begin{array}{l}\text { Interpersonal } \\ \text { meaning }\end{array} & \Leftrightarrow & \begin{array}{l}\text { subjects, objects, adjuncts, } \\ \text { specialised lexis }\end{array} \\ \text { speech function, modality } & \\ \text { Mode } & \Leftrightarrow & \text { Textual meaning } & \Leftrightarrow & \begin{array}{l}\text { clause structure, } \\ \text { exophoric/anaphoric reference, } \\ \text { lexical density }\end{array}\end{array}$

Figure 1. Relationship between register, metafunction and language (Coffin et al., 2009: 226).

The field, or topic, of a text results from the description of several of its features, which include not only the topic being discussed, but also the social activity that is 
taking place, the degree of specialization with which the topic is dealt, and from which angle -objective or subjective - it is represented. These elements can be uncovered by analyzing the subjects and complements of every clause, as subjects which occupy a thematic - initial - position tend to determine the topic of the text (Halliday, 2004: 73). Likewise, the subjects of the clauses are closely connected to the angle of representation, in as much as subjectivity is frequently associated to first and second person subjects. The complements and adjuncts that are mentioned in each clause also determine the topic, and the social activity of the text. Language choices are not only connected to the role that words have in a sentence, but also to the degree of specialization they evoke. The more specialized a word is, the more specialized we expect its audience, and therefore its context, to be. Although they frequently go unnoticed, simple choices like the ones that have just been explained transmit meaning about the context.

The tenor, or participant identification, of a text is related to the social roles and the social status in terms of power that is attributed to participants in the communicative situation. This social power is frequently linked to a degree of social distance that is established between them, and to the expectations that the speaker or writer has about the behaviour of the other interlocutor(s). As in the case of the field, this contextual variable can be uncovered by doing a very simple linguistic analysis, related to the identification of predominant speech functions in the text, the degree of formality and the terms of address employed, and the appearance, or not, of modality and evaluative language. The choice between declarative, imperative and interrogative sentences gives us information about the type of interaction that is taking place, which could be merely informative, or which could involve some type of demand. Besides, those choices serve to assign social roles to discourse participants; social roles which are emphasized, or downplayed, by means of terms of address, (in)formal language, and the appearance of evaluative forms.

Finally, the type of language used is always determined by the difference between written and spoken modes. Each of them has its own defining features in terms of interactivity, spontaneity and the distance that is established between language and the place and time of communication. All these aspects can be uncovered by considering elements such as the complexity of clauses and phrases, the appearance of interruptions, overlaps, repetitions or corrections, and the frequency of anaphoric (textual) or exophoric (contextual) references.

As it can be seen in table 1 , in this article we aim to provide a basic tool for the analysis of texts which can give us information about the context where the analysed texts are used. This can help us gather a bank of materials which can be selected depending on the language functions that we want our students to acquire and on the defining features of the context where the classroom takes place. 
Table 1. Summary of methodological approach

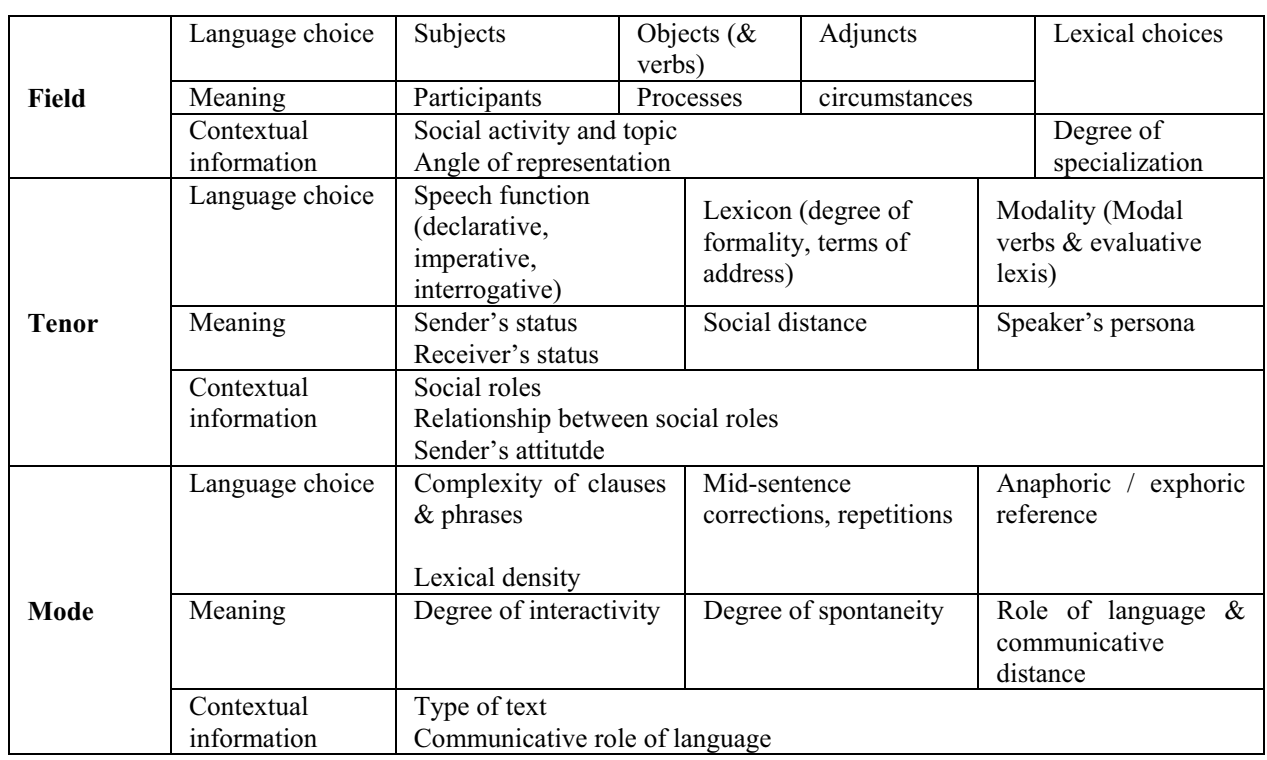

\section{Corpus}

Our hypothesis has been tested with texts aimed at $3^{\text {rd }}$ and $4^{\text {th }}$ year in a Spanish primary school, i.e. children aged between 8 and 10 . The subject chosen for this research is Science because, in the current bilingual trend that is being established in Spanish schools, this is one of the most popular subjects chosen to implement CLIL approaches. Nevertheless, the choice of scientific aspects as the ones to be taught in English is controversial, mainly due to the complexity of some of its concepts.

The choice of science texts proves to be an interesting one, as previous research about the defining features of scientific discourse have been done (Moss, 2000). Most authors note that even if this genre is aimed at making hypothesis, testing, or reformulating, these are in fact not shown because of a very static and formal use of the language, which is mainly characterized by a frequent use of technical lexis. Science texts are difficult for students to decade, particularly for the initiated, who find them difficult to read and understand (Halliday \& Martin, 1993).

Notwithstanding, one can wonder how science is taught in contexts where English is the L1, and whether the language used in them is only determined by their scientific topic, or tenor contextual aspects, such as the age of the intended audience are also considered. This led us onto another debate that is taking place in the EFL classroom: the choice between native and non-native texts, and the use of authentic material. A common argument in this debate is connected to the importance of using only materials produced by native people, so that exposure and production of English are maximized (Bradshaw, 2006). 
Taking these three issues into account, we considered the importance of comparing texts about science prepared for a classroom context as written by native and non-native speakers of English. This could help teachers decide which ones can be better exploited in the classroom, not only in terms of the acquisition of language, but also taking into account that children should also learn scientific content by means of them. For purely contrastive reasons, texts written in Spanish have been also taken into account, so that different linguistic choices between the two sets of texts can be explained, or not, as a cultural influence.

The corpus of texts that has been analysed in this research is summarised in table 2, where the abbreviation NN stands for Non-Native, $\mathrm{N}$ stands for Native and $\mathrm{S}$ stands for Spanish. All the texts with the same number deal with the same content and topic, so as to compare their differences in terms of lexis, grammar complexity, and the relationship that these features have with functional and contextual variables. Both Spanish and Nonnative texts have been extracted from textbooks used in Spanish schools, whereas British and American English native texts have been taken from different web pages designed for children learning. Although particular topics within the Science course have been chosen at random, there are parallelisms between the curriculum for the second cycle of primary in the Spanish Education System and Key Stage 2 in the National Curriculum in England.

Table 2. Corpus of texts for the analysis

\begin{tabular}{|c|c|c|c|c|c|c|}
\hline $\begin{array}{l}\text { Curricular } \\
\text { correspondence }\end{array}$ & \multicolumn{6}{|c|}{ CORPUS } \\
\hline $\begin{array}{l}\text { Bloque 1. El } \\
\text { entorno y su } \\
\text { conservación }\end{array}$ & \multirow{2}{*}{ N1 } & \multirow[t]{2}{*}{$\begin{array}{l}\text { "The Earth", BBC } \\
\text { - KS2 Bitesize: } \\
\text { Science - Earth, } \\
\text { Sun and Moon. }\end{array}$} & \multirow{2}{*}{ NN1 } & \multirow{2}{*}{$\begin{array}{l}\text { "The rotation of the } \\
\text { Earth", Essential } \\
\text { Science 3. Richmond } \\
\text { Publishing/Santillana. }\end{array}$} & \multirow{2}{*}{ S1 } & \multirow{2}{*}{$\begin{array}{l}\text { "La tierra gira", } \\
\text { Conocimiento del } \\
\text { Medio 3, Proyecto La } \\
\text { Casa del Saber. } \\
\text { Santillana. }\end{array}$} \\
\hline $\begin{array}{l}\text { Scheme work. } \\
\text { Physical Processes }\end{array}$ & & & & & & \\
\hline $\begin{array}{l}\text { Bloque } 3 \text {. La salud } \\
\text { y el desarrollo } \\
\text { personal }\end{array}$ & \multirow{2}{*}{ N2 } & \multirow[t]{2}{*}{$\begin{array}{l}\text { "Your Lungs and } \\
\text { Respiratory } \\
\text { System", How the } \\
\text { body works. }\end{array}$} & \multirow{2}{*}{ NN2 } & \multirow{2}{*}{$\begin{array}{l}\text { "The respiratory } \\
\text { system", Essential } \\
\text { Science 4. Richmond } \\
\text { Publishing/Santillana. }\end{array}$} & \multirow{2}{*}{ S2 } & \multirow{2}{*}{$\begin{array}{l}\text { "El aparato } \\
\text { respiratorio", } \\
\text { Conocimiento del } \\
\text { Medio 4, Proyecto La } \\
\text { Casa del Saber. } \\
\text { Santillana }\end{array}$} \\
\hline $\begin{array}{l}\text { Scheme work: Life } \\
\text { processes and } \\
\text { living things } \\
\text { 4. ANALYSIS }\end{array}$ & & & & & & \\
\hline
\end{tabular}

At first sight, most nonfiction texts have some common characteristics: introductory titles, short paragraphs, key words in bold letters and pictures with captions that accompany the written text. However, if we have a closer look, some differences can be noticed. Even if all the texts deal with the same topic, particularly in relation to vocabulary, type of expressions used, pictures and diagrams, or the importance given to different contents between native and non-native texts.

Our first expectation was to find native texts to be more difficult and complex to understand for a user of English as a L2. Nevertheless, it can be observed that the grammatical complexity of Spanish - which is not an obstacle for communication in the 
case of $\mathrm{S} 1$ and $\mathrm{S} 2$ - is calqued into NN1 and NN2, which renders them even more complex for the potential intended audience: children. Complexity does not stem from purely observable aspects, as all the analysed texts have short paragraphs which are well structured, with apparently simple sentences.

Things change slightly when we perform a close analysis of the way contextual variables are realized in the texts. In the six texts, the uncovered field shares some features, particularly the social activity that is being done through them, which is basically related to giving information and explaining facts. The topic is similar in all the texts with number 1, which deal with aspects related to the rotation of the Earth and its consequences for having day and night, and texts with number 2, which are related to the respiratory system. Likewise, all the texts share a similar angle of representation, which is quite objective. This is the consequence of a prominence of third person subjects, such as «the earth» or «la tierra» in N1, NN1 and S1, and "your lungs» in N2, "pulmones», and «oxígeno» in S2 and «the respiratory system», «oxygen» and «air» in NN2.

Although objectivity is a key aspect in all the texts, there are significant differences in the way in which that is connected to the degree of specialization that texts have. Given that these texts are related to Science, we can see that this is emphasized in Spanish-based text (both written in Spanish (S1 and S2) and written in English in a Spanish context (NN1 and NN2)), by using highly specialized words. In NN1, many difficult words - some of which have a clear Latin origin - are used to explain the rotation of the Earth, particularly «rotation», «axis», «surface», and «sphere». The same degree of specialization can be seen in NN2, which begins by saying that «the respiratory system is made up of the following organs: nostrils, trachea, two bronchial tubes and two lungs.» In this case, organs of the respiratory system are simply named, but there is no description of their functions, shape or place in the human body throughout the text. These uses of specialized language result in an increased difficulty for understanding, as processing the information becomes difficult for children not only because of the use of unusual words which are not explained, but also because these words appear in texts produced in the L2.

On the contrary, specialized vocabulary is used differently on native texts (N1 and N2), where some technical words are also used, but they appear in a context surrounded by references that allow readers to connect those difficult terms to their known reality. This difference becomes obvious if we compare examples 1 and 2, as the word "sphere» appears in both cases. However, whereas in NN1 the author assumes the child knows what a sphere is, in N1 this shape is explained by relying on known things, such as «a squashed ball». Given the connection between language and our social experience as individuals (Langacker, 2008), children can easily understand and picture what a sphere is by reading text N1, as its defining characteristic is part of their known reality, and hence of their social knowledge; something which does not happen in the case of NN1.

(1) The Earth is a sphere. (NN1)

(2) The Earth is round, like a ball, but it is also slightly squashed. We say that its shape is roughly spherical. (N1)

One of the most interesting aspects where native and non-native texts differ is in the way that the contextual relationship between communicators is textually constructed, 
i.e. the tenor. One of the traditional images of teaching is a conception of the teacher as an objective information giver and the student as an information seeker. This involves using declarative sentences with third person references, formal language, not many modal expressions, and formal, if any, terms of address. Generally speaking, this is the type of conception that we find in the texts produced in the Spanish context, which are characterized by declarative sentences used basically to present facts. This is achieved by a common use of third person references accompanied by either a present tense emphasizing the «real» characteristic of what is being said - or a past tense - which recalls the historicity of the described event. This can be easily observed in examples 3 , 4 and 5.

(3) El movimiento de rotación de la Tierra da lugar a los días y las noches. (S1)

(4) On the part of the Earth facing the Sun, it is day. (NN1)

(5) Air enters our body through the nose and mouth. It passes through the nostrils. It goes down through the trachea and the bronchial tubes, and into the lungs. (NN2)

This distant relationship is downplayed in texts produced in an English context, where we can see that information is presented from either the point of view of the reader, as in N2, or both communicators, as in N1. This is achieved by the use of first and second person pronouns, which contribute to downplaying the communicative - and social distance between the teacher and the student. It could be argued that this contributes to a closer relationship between the student and the topic which is being explained, as it is presented as part of his/her known reality, hence resulting in a better comprehension, as we can see in examples 6 and 7 .

(6) The Earth is round, like a ball, but it is also slightly squashed. We say that its shape is roughly spherical. (N1, our emphasis)

(7) Your lungs make up one of the largest organs in your body [...] Your lungs are in your chest $[\ldots]$ Your lungs are protected by your rib cage, which is made up of 12 sets of ribs... (N2, our emphasis)

Finally, some differences can be also observed in the way that the written mode is understood in the Spanish and English contexts, with texts produced in Spanish being slightly more complex, both in the construction of sentences, and in the modifiers used. Even if they are written in English, NN1 and NN2 seem to reflect a Spanish conception about writing which differs slightly from the simplicity of English texts. This seems to be connected to social beliefs about when new information shall be given, as we can see in examples 8 and 9. In NN1 the theme of the sentence always corresponds to the new information which is being explained, whereas in N1 the theme recalls the given information (Halliday 2004), i.e. that which is already known. The rigidity of the Spanish pattern could have consequences in terms of processing, as it forces the reader - the children - to focus always on the new element, instead of departing from references to a known reality.

(8) On the part of the Earth facing the Sun, it is day. On the part of the Earth facing away from the Sun, it is night. (NN1) 
(9) It is day on the part of the Earth that is facing the Sun. It is night on the part of the Earth that is facing away from the Sun. (N1)

The analysis shows how certain features such as specialized language, communicative distance or interactivity significantly vary depending on the text where they appear, and on the context in which this text has been produced. Awareness about these differences is important for the teacher, as it could have important consequences in the process of decoding and conveying meanings, and therefore, in the learning process of our students. As Wray \& Lewis (1997: 31) note «all interactions with texts in order to learn will involve a much more complex amalgam of mental processes than a simple linear list of stages», and among those aspects socio-cultural beliefs about the way in which a text should be written are important and have an impact on L2 learning.

\section{Conclusions}

In this paper, we have tried to emphasise the importance and the validity of analysing discourse when choosing classroom materials. If the teacher is aware of the socio-cultural references that permeate a text, and how they relate to expectations about discourse and the fulfillment of communicative metafunctions, it will become easier for him/her to select materials not only on the basis of content, but also on the basis of language. This should be one of the primary aims of CLIL classrooms, where the L2 is not the objective of instruction but the means of instructions.

Awareness about how contextual features influence and determine the construction of discourse is significant, particularly if some traditional beliefs about education are to be counteracted. The analysis done for this research does not only show that communicative metafunctions are constructed in different ways in texts produced by English native speakers and Spanish ones, but also that the beliefs they have are different. It could be argued that given the complexity that learning in a L2 entails, working with texts that are more learner-centered has a better outcome, mainly because more interaction is allowed. Therefore classroom materials are not only devised as a static source of information, but as a tool which can help in the learning process.

The type of analysis proposed in this article can help teachers identify those linguistic features which make a text understandable and easier to decode for students. This can be useful not only for choosing texts, but also for adapting them, chiefly in relation to aspects such as the degree of specialization, interactivity, references to reality, and social distance in communication. All these aspects could help us device a sample questionnaire that could be applied to a corpus of materials so that the teacher can choose among them depending both on the language aspects and the contents to be taught. For the context devised in this research, some of the questions used were «is the language very technical?», «are scientific terms clearly explained?», «are there references to known reality in the text?», or «can the reader feel involved in the reading process by means of pronominal choices?». These helped us in selecting the native texts, which turned to be more fruitful when used in the classroom both in terms of the acquisition of content and of L2 structures. 
Taking the above into account, this paper proposes discourse analysis based on functional grammar as a useful tool which can facilitate the process of reading non-fiction texts, and hence subsequent text selection. Choosing appropriate texts - not only because of the language used but also because of their functional use of language - can improve the process of learning and teaching, which may, indeed, result in some kind of relief for the overwhelmed teacher.

\section{REFERENCES}

\subsection{Primary sources}

BBC (2010) «The Earth», in BBC-KS2. Bitesize: Earth, Sun and Moon, available from: http:// www.bbc.co.uk/schools/ks2bitesize/science/physical_processes/earth_sun_moon/read2.shtml, accessed 01/09/2010.

The Nemours Foundation (1995-2010). «Your Lungs and Respiratory System», Kidshealth for Kids, available from: http://kidshealth.org/kid/htbw/lungs.html, accessed 01/09/2010.

Santillana (2006). Essential Science 3.Inglés, educación primaria. Madrid: Santillana/Richmond Publishing

Santillana (2008). Essential Science 4.Inglés, educación primaria. Madrid: Santillana/Richmond Publishing

Santillana (2008) Conocimiento del medio 3. Proyecto «La casa del Saber». Madrid: Santillana/ Richmond Publishing.

Santillana (2008) Conocimiento del medio 4. Proyecto «La casa del Saber». Madrid: Santillana/ Richmond Publishing.

\subsection{Works cited}

Bradshaw, C. (2006). «Taboo or not taboo?», in English Teaching Professional, 46: 22-24.

Brown, G. \& G. Yule. (1983). Discourse Analysis. Cambridge: Cambridge University Press.

Coffin, C., J. Donohue, \& S. North. (2009). Exploring English Grammar. From Formal to Functional. London: Routledge.

Halliday, M. A. K. (1999). The Notion of «Context» in Language Education. In M. Ghadessy (ed.), Text and Context in Functional Linguistics. Amsterdam: John Benjamins: 1-24.

Halliday, M.A.K. \& J.R. Martin. (1993). Writing Science. Literacy and Discursive Power. London: Routledge.

Halliday, M.A.K. (2004). An Introduction to Functional Grammar. London: Hodder education.

Langacker, R.W. (2008). Cognitive Grammar. A Basic Introduction. Oxford: Oxford University Press.

McCarthy, M. \& R. Carter. (1994). Language as Discourse. Perspectives for Language Teaching. Essex: Pearson

Moss, M.G. (2000). «The language of school textbooks and the ideology of science», Zona Próxima. Revista del Instituto de Estudios en Educación Universidad del Norte 1: 44-55.

Wray, D. \& M. Lewis. (1997). Extending Literacy. Children Reading and Writing Non-Fiction. London: Routledge. 